\title{
章 \\ Painel SRT para teste de paternidade em caprinos
}

\author{
[SRT panel for paternity testing in goats]
}

\section{"Artigo Científico/Scientific Article"}

\author{
Laura Leandro da Rocha ${ }^{1}$, Amparo Martinez Martinez ${ }^{2}$, Juan Vicente Delgado ${ }^{2}$, \\ Manoel Adrião Gomes Filho ${ }^{3}$, Maria Norma Ribeiro ${ }^{1}$
}

\begin{abstract}
${ }^{1}$ Departamento de Zootecnia, Universidade Federal Rural de Pernambuco, Serra Talhada -PE, Brasil.
${ }^{2}$ Departamento de Genética, Universidad de Cordoba, Campus de Excelencia Internacional Agroalimentario, Espanha.

${ }^{3}$ Departamento de Morfologia e Fisiologia Animal, Universidade Federal Rural de Pernambuco, Recife-PE, Brasil.

*Autor para correspondência/Corresponding author: E-mail: laura_rocha77@yahoo.com.br
\end{abstract}

\begin{abstract}
Resumo
Acasalamentos duvidosos são uma das causas dos erros nos programas de conservação e de melhoramento genético de raças. Os testes de paternidades são ferramentas que podem contribuir para minimizar esses erros pois tem sido usados para identificar paternidade duvidosa. O presente trabalho teve como objetivo definir um painel para teste de paternidade em caprinos para auxiliar programas de conservação e melhoramento de raças. Foram genotipados 381 animais de 10 populações caprinas sendo seis ecotipos locais brasileiros e quatro raças exóticas utilizadas atualmente no Brasil (Alpina, Anglo-Nubiana, Boer e Saanen). Realizou-se nove sistemas multiplex, totalizando 27 microssatélites. Foram estimados o PIC, as probabilidades de exclusão dos marcadores e o equilíbrio de Hardy-Weinberg (EHW) nas populações, seguida de determinação da probabilidade de identidade (PI). Para o sistema de 27 microssatélites a probabilidade de exclusão combinada (PE) foi de 0,999 e 0,999 ( $\mathrm{PE}_{1}$ e $\left.\mathrm{PE}_{2}\right)$ e, 21 microssatélites apresentaram $\mathrm{PIC}>0,60$, onde quatro apresentaramse monomórficos em algumas populações. Para compor o novo painel foram escolhidos 9 marcadores dos quais oito comuns aos dois grupos estudados (caprinos locais e exóticos), sendo o BM1818 mais informativo nas populações locais e, o marcador BM6506 nas populações exóticas. A probabilidade de exclusão combinada com o grupo dos microssatélites foi de 0,994 e 0,999 $\left(\mathrm{PE}_{1}\right.$ e $\left.\mathrm{PE}_{2}\right)$. Baseado no cálculo das probabilidades de identidade dentro das populações foi possível discriminar um indivíduo entre um milhão $\left(10^{6}\right)$. Os resultados indicaram a possibilidade de empregar poucos microssatélites na investigação de paternidade em caprinos, com alto grau de confiabilidade, minimizando assim custos para o criador.
\end{abstract}

Palavras-chave: recursos genéticos; pequenos ruminantes; microssatélites; probabilidade de exclusão.

\begin{abstract}
Dubious mating is one of the causes of errors in conservation and breeding programs. Paternity tests are tools that can help minimize these errors as they have been used to identify questionable matings. The present work had the objective of defining a panel for paternity testing in goats as an aid to conservation and breeding programs. A total of 381 animals from 10 goat populations were genotyped, including six Brazilian local and four exotic breeds currently used in Brazil (Alpine, Anglo-Nubian, Boer, and Saanen). Nine multiplex systems were performed, totaling 27 microsatellites. The Polymorphic information content (PIC), the marker exclusion probabilities and the Hardy-Weinberg equilibrium (HWE) in the populations were estimated, followed by determination of the likelihood of identity (PI). For the 27 microsatellite system, the combined exclusion probability (EP) was 0.999 and 0.999 (EP1 and EP2), and 21 microsatellites presented PIC > 0.60, and four were monomorphic in some populations. To compose the new panel, nine markers were chosen, of which eight were common to the two studied groups (local and exotic goats). The BM1818 was more informative in the local populations and the BM6506 marker in the exotic populations. The probability of exclusion combined with the microsatellite group was 0.994 and 0.999 (EP1 and EP2). Based on the calculation of identity probabilities within populations, it was possible to discriminate between one million individuals $\left(10^{6}\right)$. The results indicated the possibility of using a small number of microsatellites to investigate paternity in goats, with a high degree of reliability, thus minimizing costs for the farmer.
\end{abstract}

Keywords: genetic resources; small ruminant; microsatellites; probability of exclusion. 


\section{Introdução}

Um plano de gestão genética adequado deve ter como alvo evitar o acasalamento entre indivíduos aparentados, minimizando a consanguinidade e, com isso, assegurar a conservação de uma raça e planos de avaliação genética seguros (Carneiro et al., 1999). Ao se conhecer a estrutura genética de uma população pode-se classificá-la quanto ao grau de ameaça, de acordo com os critérios propostos pela FAO (2012).

Boettcher et al. (2014) relataram que a procura por produtos de origem animal vem aumentando significativamente, intensificando assim a concorrência por recursos para elevação da produtividade e eficiência dos sistemas pecuários, sendo necessário a manutenção e conhecimento da diverisidade genética bem como dos produtos derivados.

Com o desenvolvimento da genética molecular, equipamentos e softwares para a manipulação dos dados têm sido utilizados como ferramentas poderosas para o estudo genético e controle de espécies ameaçadas, permitindo assim a identificação de possíveis introduções de genótipos e detectando de forma eficiente relações de parentesco.

A análise de DNA é uma poderosa ferramenta para a verificação do grau de parentesco e identificação individual dos animais. A forense humana é líder nessa área, tendo desenvolvido painéis de marcadores microssatélites altamente informativos para populações humanas (DeNise et al., 2004). Curi e Lopes (2001) relataram que a divulgação de marcadores moleculares tornou fácil a quantificação da variabilidade genética existente entre indivíduos e populações, assim como a realização de teste de paternidade em vegetais, animais e humanos, existindo, hoje, grande número de marcadores que podem vir a serem utilizados em laboratório e até mesmo propostos ao MAPA para inclusão na relação de marcadores para testes de paternidade em animais domésticos.

Várias são os fatores que contribuem para paternidades errôneas. Estas causas provocam confusão nos controles zootécnicos simples, na inseminação artificial e tranferências de embriões, os quais podem favorecer erros e fraudes (Madalena, 1999; Gurgel, 1998). Como as avaliações genéticas são a base para qualquer programa de seleção, os erros nas genealogias podem comprometer qualquer programa, afetando sua eficiência e credibilidade do programa de seleção.

A utilização de teste de paternidade é, ferramenta essencial para regularizar a implementação de sistemas de registros, no controle de identificação de animais. Os testes de paternidade não são suficientes para provar maternidade e paternidade. Eles são usados para excluir uma suspeita de paternidade de um indivíduo quando esse não possui alelo nas progênies avaliadas.

A eficiência no teste de paternidade não depende apenas do número de marcadores utilizados, mas do nível de informação que estes fornecem, a qual é determinada pelos valores de PIC, probabilidade de exclusão e heterozigosidade. Estes valores dependem do número de alelos e da frequência de distribuição destes alelos nas populações (Curi et al., 2002). A utilização de conjuntos de primers em uma mesma reação de PCR (PCR multiplex) requer o estabelecimento de condições necessárias para a amplificação, levando-se em conta vários fatores, como a escolha e o desenho do primer; número de primers a serem utilizados na mesma reação, concentrações de enzima, tampão, tempo, equilíbrio das regiões a serem amplificadas; o tamanho relativo dos fragmentos; a dinâmica dos primers; e a otimização da técnica da PCR para muitos fragmentos. Todos esses aspectos encontram-se detalhadamente em Chamberlain et al. (1988), Edwards e Gibbs, (1994), Dzialuk et al. (2005) e Martínez (2005a).

Alguns sistemas de PCR multiplex podem ser tão simples como combinar dois conjuntos de primers para uma reação, outros devem ser desenvolvidos com cuidados para a região a ser amplificada, o tamanho dos fragmentos, da dinâmica dos primers, e a otimização da técnica da PCR para acomodar múltiplos fragmentos, além do uso de fragmentos de DNA marcados com fluorescências (Edwards e Gibbs, 1994; Dzialuk et al., 2005).

O uso de PCR multiplex reduz o tempo e custo da análise, bem como o número de marcadores utilizados, com grau de polimorfismo que permita a verificação da paternidade, na confirmação de parentesco duvidoso. Os microssatélites ou SRTs (Short Tandem Repeats) 
consistem em sequências curtas de nucleotídeos (1$6 \mathrm{pb})$ que estão distribuídos em todo o genoma e se repetem diversas vezes. Por apresentarem-se altamente polimórficos, herança co-dominante e baixo custo, passaram a ser usados nos estudos de genética de conservação, sendo utilizados em cruzamentos endogâmicos com objetivo de manter ou maximizar a diversidade genética, bem como para descobrir as relações entre indivíduos, grupos, populações, raças ou espécies para planos de acasalamentos ou identificação de unidades de conservação (Marshall et al., 1999; Lins et al., 2006). Também são utilizados em mapeamento físico e genômicos, estudos de genética evolutiva e de populações, bem como em investigações criminais.

Segundo Tommasini et al. (2003), as melhorias na tecnologia de marcadores moleculares, como a amplificação de DNA em PCR multiplex, que consiste na amplificação simultânea de mais de um SSR em uma única reação, combinado com o uso de fluorescências para detecção automática do tamanho e clonagem do DNA, permitindo uma rápida e precisa nas genotipagens.

Devido à crescente preocupação e procura por produtos naturais, saudáveis, bem como a origem destes, o desenvolvimento de painéis tem servido de base para identificar indivíduos, possibilita a rastreabilidade e pode ser útil também no futuro para assegurar os produtos derivados de determinadas raças. Os programas de melhoramento genético para caprinos de raças e grupos locais bem como para as exóticas, no Brasil, ainda são incipientes e as iniciativas de criação de banco de dados se devem exclusivamente a esforços isolados de instituições de pesquisa e dos próprios criadores.

Com base nesse panorama e pelo fato da paternidade ser de difícil detecção por análises morfológicas em caprinos, objetivou-se desenvolver um painel de microssatélites para futuros teste de paternidade em raças caprinas.

\section{Material e Métodos \\ Material biológico}

Foram utilizados 381 animais referentes a 10 populações caprinas, sendo seis raças locais brasileiros (Azul, Canindé, Graúna, Marota, Moxotó e Repartida) e quatro raças exóticas utilizadas atualmente no Brasil (Alpina, AngloNubiana, Boer e Saanen).

\section{Extração do DNA e reação de amplificação dos microssatélites}

Foram coletadas amostras de bulbos capilares de cada animal, colocados em envelopes e acondicionados em freezer até o momento da extração do DNA. Foram analisados 27 marcadores microssatélites TGLA122 (George set al., 1992); BM1329, BM6506, BM6526, BM8125 (Bishop et al., 1994); CSSM66, ETH225 (Barendese et al., 1994); CSRM60, SPS115 (Mooreet et al., 1993), MM12 (Mommens et al., 1994); ILSTS011, MAF209, MAF65, SRCRSP8 (Luikart et al., 1999); HSC, McM527, INRA6 (Isag, 2002); BM1818, INRA023 (Li et al., 2002); CSRD247 (FAO, 2004); OarFCB11, OarFCB48, OarFCB304 (Yang et al. 1999); ETH10 (SolinasToldo et al., 1993); INRA63, INRA5 (Vaiman et al., 1994), HAUT27 (Thieven et al., 1997), para a realização das análises. Amplificados pelo método da PCR, segundo protocolo da Martínez et al. (2004). As informações foram recolhidas e analisadas através do programa Genescan Analysis $^{\circledR}$, versão 3.12 , e Genotyper v. 3.7 para análise das bandas e identificação dos alelos de cada microssatélite.

\section{Análise estatística}

O cálculo da heterozigosidade (observada e esperada) foi realizado através do programa Genetix v.4.03 (Belkhir, 2004). O conteúdo de informação polimórfica (PIC), que informa a qualidade do marcador estudado, foi calculado para cada loco a partir do Microsatéllite Toolkit (Park, 2001), com auxílio do Microsoft Excel ${ }^{\circledR}$, segundo o algoritmo descrito por Bolstein et al. (1980):

$$
P I C=1-\left[\sum_{i=1}^{n} p_{i}^{2}\right] \sum_{i=1}^{n-1} \sum_{j=i+1}^{n} 2 p_{i}^{2} p_{j}^{2}
$$

onde $\mathrm{p}_{\mathrm{i}}$ é a frequência do alelo $\mathrm{i}^{\text {th }}$.

Todos os parâmetros analisados consideraram os indivíduos em uma única população e populações separadas

$\mathrm{O}$ teste exato do EHW foi realizado pelo programa Genepop v. 3.1 (Raymond e Rousset, 1995), segundo Guo e Thompson (1992), mediante o algoritmo da cadeia de Monte Carlo Markov (100 batches, 5000 interações e um número de demorização de 10000), o qual permite discriminar os microssatélites em desequilíbrio nas populações. Realizou-se a análise de probabilidade de exclusão (PE) que representa a probabilidade de um animal 
escolhido aleatoriamente, não ser o pai/mãe de uma determinada cria. A probabilidade de exclusão 1 $\left(\mathrm{PE}_{1}\right)$ estima a chance de exclusão quando conhecido o genótipo do filho e de um possível progenitor, já para $\mathrm{PE}_{2}$, além dos genótipos citados, tem-se o genótipo de um dos verdadeiros pais. A probabilidade de exclusão combinada para todos os locos foi dada por: $\mathrm{PEC}=1-\left(1-\mathrm{PE}_{\mathrm{n}}\right)^{\mathrm{k}}$, sendo $\mathrm{n} \mathrm{o}$ número de locos avaliados e $\mathrm{k}$ a probabilidade de exclusão de cada marcador. As probabilidades de exclusão $\mathrm{PE}_{1}, \mathrm{PE}_{2}$ e a $\mathrm{PEC}$ (probabilidade de exclusão combinada) foram calculadas através do programa Cervus v. 2 (Marshall et al., 1998), segundo algoritmo de Jamieson (1994).

Com base nos parâmetros supracitados, foram escolhidos microssatélites para compor um novo painel para testes de paternidade em caprinos. Determinou-se a probabilidade de identidade (PI), segundo estabelecido por Paetkau et al. (1995) para cada um dos microssatélites escolhidos em cada população e a probabilidade de identidade combinada. Os resultados foram gerados a partir do programa Identity 1.0 (Wagner e Sefc, 1999), calculada segundo a fórmula:

$$
P I=\sum_{i} p_{i}^{4}+\sum_{i} \sum_{j>i}\left(2 p_{i} p_{j}\right)^{2}
$$

Onde: $p_{i}$ e $p_{j}$ são as frequências dos alelos $i^{\text {th }}$ e $j^{\text {th }}$ em uma dada população.

\section{Resultados}

Todos os locos de microssatélites amplificaram normalmente para algumas populações. Dos 27 microssatélites utilizados, vinte (BM1329, BM1818, CSRD247, SPS115, HSC, MM12, SRCSP8, INRA63, SPS115, TGLA122, CSRM60, CSSM66, McM527, OarFCB11, OarFCB304, MAF65, ETH225 e ETH10, INRA23 e HAUT27) foram propostos pelo ISAG entre 2001 e 2002, para compor painéis de teste de paternidade em bovinos, ovino e caprinos. Desses, os marcadores OarFCB11 e OarFCB304 compõem a lista de microssatélites recomendados pelo MAPA (2004) para esse tipo de teste, e três (CSRD247, MAF65, INRA23) entraram na lista recomendada pelo ISAG, como primer informativos para teste em caprinos (ISAG, 2016).

Os microssatélites apresentaram-se polimórficos com grande diferenciação nas frequências alélicas. A média de alelos nas populações exóticas variou de 7,30 (Alpina) a 5,09 (Boer). Já para as populações locais foram encontrados valores variando de 6,74 (Graúna) a
5,70 (Marota). Para os locos MAF209, HAUT27 e INRA5 verificaram-se monomorfismo em algumas populações.

$\mathrm{Na}$ Tabela 1 encontram-se a heterozigosidade esperada $\left(\mathrm{H}_{\mathrm{e}}\right)$ e observada $\left(\mathrm{H}_{\mathrm{o}}\right)$, o número de alelos, o conteúdo de informação polimórfica (PIC) e a probabilidade de exclusão $\left(\mathrm{PE}_{1}\right.$ e $\left.\mathrm{PE}_{2}\right)$ para os locos analisados. Verificou-se heterozigosidade média de 0,730 , com variação de 0,2152 para o loco MAF209 a 0,889 para o loco CSSM66, sendo este último com maior número de alelos. Verificou-se 21 marcadores com PIC acima de 0,60, com média de 0,699 e heterozigosidade elevadas. Apenas três marcadores (SPS115, MAF209 e ETH225) apresentaram valores baixos de PIC $(<0,50)$. O loco MAF209 assim como o ETH225 apresentaram polimorfismo baixo, apesar do primeiro ser recomendado para estudo de diversidade em populações caprinas, são marcadores relacionados a espécie ovina.

A análise dos desvios para o EHW foi realizada considerado os indivíduos de acordo com suas respectivas populações, onde o marcador CSSM66 apresentou-se em desequilíbrio em oito populações. De modo geral, as populações com maiores números de marcadores em desequilíbrio foram as de caprinos locais, como pode ser visto nas populações Moxotó e Marota. Nas raças exóticas, a população Alpina apresentou desequilíbrio em sete marcadores. O loco MAF209 não foi observado em quatro populações (Azul, Moxotó, Marota e Graúna) e apresentou-se monomórfico em quatro populações sendo três exóticas (Alpina, Anglo-Nubiana e Saanen) e uma local (Canindé).

Verificou-se no sistema dos 27 microssatélites utilizados uma probabilidade de exclusão combinada de 0,999 e 0,999 ( $\mathrm{PE}_{1}$ e $\left.\mathrm{PE}_{2}\right)$, respectivamente. Considerada alta para teste de paternidade. Na escolha dos microssatélites para o novo painel, considerou-se o comportamento quanto ao EHW nas populações, o grau de polimorfismo, as $\mathrm{PE}_{1}$ e $\mathrm{PE}_{2}$, considerando as fluorescências e o menor número possível de reações de multiplex que permitisse a leitura em um só gel, bom poder discriminante entre os indivíduos para o teste de paternidade.

Os microssatélites CSRM60, CSSM66 e INRA6 apesar de apresentarem-se informativos (PIC>0,70) e com número de alelos acima de 10 foram retirados do painel, pois o primeiro requer uma especificação técnica na amplificação, como a temperatura de anelamento, o segundo por 
apresentar desequilíbrio em $80 \%$ dos grupos populacionais estudados e o terceiro por ter apresentado desequilíbrio em quatro grupos, além de não amplificar em uma delas.

Tabela 1. Número de alelos $(\mathrm{Na})$, número de animais $(\mathrm{N})$, heterozigosidade esperada $\left(H_{e}\right)$, heterozigosidade observada $\left(H_{o}\right)$, Conteúdo de Informação Polimórfica $(P I C)$ e Probabilidade de Exclusão $\left(P E_{1}\right.$ e $\left.P E_{2}\right)$, em função dos locos analisados.

\begin{tabular}{|c|c|c|c|c|c|c|c|}
\hline Locos & $N_{a}$ & $N^{a}$ & $\boldsymbol{H}_{e}$ & $\boldsymbol{H}_{o}$ & PIC & $P E_{1}$ & $P E_{2}$ \\
\hline CSSM66 & 29 & 368 & 0,8891 & 0,5924 & 0,8804 & 0,646 & 0,785 \\
\hline SRCSP8 & 12 & 376 & 0,8310 & 0,6436 & 0,8099 & 0,499 & 0,669 \\
\hline MM12 & 16 & 377 & 0,8242 & 0,7825 & 0,8072 & 0,502 & 0,672 \\
\hline BM6526 & 17 & 374 & 0,8345 & 0,7594 & 0,8210 & 0,530 & 0,696 \\
\hline CSRM60 & 10 & 371 & 0,8279 & 0,7736 & 0,8058 & 0,488 & 0,660 \\
\hline INRA6 & 13 & 238 & 0.8675 & 0.6639 & 0,853 & 0,581 & 0,737 \\
\hline OarFCB304 & 18 & 379 & 0,8309 & 0,6596 & 0,8162 & 0,520 & 0,688 \\
\hline HSC & 17 & 344 & 0,8432 & 0,7292 & 0,8265 & 0,534 & 0,698 \\
\hline TGLA122 & 12 & 379 & 0,8334 & 0,7124 & 0,8115 & 0,437 & 0,668 \\
\hline CSRD247 & 10 & 379 & 0,7983 & 0,6992 & 0,7697 & 0,430 & 0,608 \\
\hline ILSTS11 & 09 & 380 & 0,8117 & 0.6026 & 0,7846 & 0,451 & 0,627 \\
\hline BM1818 & 10 & 364 & 0,7362 & 0,6484 & 0,7163 & 0,370 & 0,559 \\
\hline BM8125 & 08 & 380 & 0,7860 & 0,7158 & 0,7524 & 0,402 & 0,580 \\
\hline BM1329 & 12 & 354 & 0,7518 & 0,6441 & 0,7169 & 0,364 & 0,543 \\
\hline OarFCB11 & 15 & 377 & 0,7850 & 0,6870 & 0,7627 & 0,431 & 0,611 \\
\hline MAF65 & 10 & 373 & 0,7705 & 0,5523 & 0,7390 & 0,395 & 0,573 \\
\hline OarFCB48 & 09 & 378 & 0,7137 & 0,6296 & 0,6757 & 0,321 & 0,499 \\
\hline BM6506 & 10 & 375 & 0,6614 & 0,4827 & 0,6307 & 0,273 & 0,457 \\
\hline McM527 & 09 & 375 & 0,7394 & 0,6213 & 0,6994 & 0,343 & 0,520 \\
\hline INRA23 & 08 & 89 & 0.7156 & 0.4831 & 0,669 & 0,313 & 0,488 \\
\hline INRA5 & 08 & 378 & 0.6652 & 0.6481 & 0,614 & 0,255 & 0,423 \\
\hline HAUT27 & 09 & 344 & 0.6229 & 0.5116 & 0,578 & 0,224 & 0,394 \\
\hline INRA63 & 06 & 377 & 0,6265 & 0,5066 & 0,5544 & 0,215 & 0,360 \\
\hline ETH10 & 06 & 374 & 0,6691 & 0,5214 & 0,5966 & 0,229 & 0,379 \\
\hline SPS115 & 06 & 376 & 0,5405 & 0,4362 & 0,4353 & 0,149 & 0,244 \\
\hline ETH225 & 04 & 379 & 0,4793 & 0,3826 & 0,4119 & 0,117 & 0,237 \\
\hline MAF209 & 03 & 378 & 0,2152 & 0,1191 & 0,2015 & 0,024 & 0,110 \\
\hline
\end{tabular}

PE1: Probabilidade de exclusão com a ausência do genótipo de um dos pais;

$\mathrm{PE}_{2}$ : Probabilidade de exclusão considerando o genótipo dos dois pais.

Na Tabela 2 encontram-se os marcadores candidatos ao painel para identificação de paternidade nas populações de caprinos locais e exóticas, o que possibilitou a formação de duas multiplex em cada painel. Os locos escolhidos são independentes e localizados em cromossomos distintos. A escolha também se baseou nas marcas fluorescentes, de forma que os locos marcados com a mesma fluorescência não possuíssem fragmentos de tamanhos sobrepostos, sendo este um dos motivos de descarte do microssatélite TGLA122 do painel. O número de alelos variou de 8 a 18 para os microssatélites escolhidos, pois o grau de polimorfismo do marcador é uma característica muito importante em estudos de paternidade.

$\mathrm{O}$ painel proposto consta de oito microssatélites, considerados informativos, comuns a ambos os grupos de caprinos (locais e exóticos). Para esse grupo de microssatélites a probabilidade de exclusão combinada foi de 0,994 e 0,999 ( $\mathrm{PE}_{1}$ e $\left.\mathrm{PE}_{2}\right)$, de forma que esse grupo de microssatélites pode constituir um painel para teste de paternidade em caprinos. No painel proposto observou-se que o marcador BM1818 foi o mais informativo nas populações nativas. Já no painel proposto para animais exóticos, o marcador BM6506 foi o mais informativo, compondo um painel com nove marcadores para o grupo exótico e grupo local.

Observa-se que a heterozigosidade variou de 0,524 a 0,878 no grupo exótico, e de 0,490 a 0,836 no grupo nativo para o conjunto de nove microssatélites propostos no painel. Com base nestes painéis, foi possível avaliar a capacidade de 
discriminar indivíduos, sendo a probabilidade de identidade, um estimador de identificação individual, ou a probabilidade de que dois indivíduos escolhidos ao acaso de uma população tenham genótipos idênticos em vários locos (Paetkau et al., 1995; Waits et al., 2001). A probabilidade de identidade combinada variou de $1,08 \times 10^{5}$ a $1,67 \times 10^{8}$ para os caprinos exóticos, e para os caprinos locais de $1,5 \times 10^{6}$ a $1,89 \times 10^{7}$.
Percebe-se que o cálculo das probabilidades de identidade dentro das populações permite discriminar um indivíduo entre um milhão $\left(10^{6}\right)$. Considerando os microssatélites comuns às populações exóticas e nativas, o poder de discriminação para o painel proposto para as populações exóticas foi de $6 \times 10^{8}$, e para o painel proposto para grupo de raças locais foi de $8,7 \times 10^{6}$.

Tabela 2. Painel de microssatélites para emprego em teste de paternidade, multiplex, tamanho dos alelos e número de alelos $(\mathrm{Na})$ por locos.

\begin{tabular}{ccc|ccc}
\hline Painel & \multicolumn{2}{c|}{ Grupo Local } & Painel & \multicolumn{2}{c}{ Grupo Exótico } \\
\hline Multiplex 1 & Tamanho alélico & Na & Multiplex 1 & Tamanho alélico & Na \\
\hline BM8125 & $100-128$ & 08 & BM8125 & $100-128$ & 08 \\
MM12 & $85-135$ & 16 & MM12 & $85-135$ & 16 \\
CSRD247 & $208-250$ & 10 & CSRD247 & $208-250$ & 10 \\
OarFCB304 & $130-180$ & 18 & OarFCB304 & $130-180$ & 18 \\
\hline Multiplex 2 & & & Multiplex 2 & & \\
\hline BM1818 & $254-290$ & 10 & BM6506 & $190-228$ & 10 \\
BM6526 & $145-195$ & 17 & BM6526 & $145-195$ & 17 \\
SRCRSP8 & $210-260$ & 12 & SRCRSP8 & $210-260$ & 12 \\
BM1329 & $153-185$ & 12 & BM1329 & $153-185$ & 12 \\
HSC & $270-306$ & 17 & HSC & $270-306$ & 17 \\
\hline
\end{tabular}

\section{Discussão}

A maioria dos microssatélites empregados no estudo apresentaram polimorfismo. Apenas os marcadores MAF209, ETH10, INRA5 e HAUT27 que apresentaram-se monomórficos em algumas populações. Os microssatélites com menor número de alelos também apresentaram $\mathrm{PIC}<0,50$. Os resultados corroboram com os reportados por Menezes et al. (2006) em estudos de diversidade genética de cabras, os de Oliveira et al. (2010), com caprinos locais da raça Moxotó, e Luikart et al. (1999) avaliando caprinos espanhóis (Murciano Granadina) e da raça Saanen. Martínez et al. (2005) encontraram resultados semelhantes para três marcadores (ETH10, INRA5 e HAUT27) em estudos de caracterização da cabra MurcianoGranadina. Os mesmos autores ressaltaram a importância de levar em conta à utilização destes marcadores em estudos posteriores de variabilidade genética.

O marcador MAF209 mostrou-se pouco polimórfico devido ao pequeno número de alelos nas populações estudadas. Menezes et al. (2006) e Luikart et al. (1999) encontraram resultados semelhantes para este loco. Os autores relataram que este marcador foi estudado primeiramente em ovinos e, provavelmente encontra-se em uma zona de baixa variabilidade genética para a espécie caprina. Sendo considerado um iniciador homólogo aos caprinos (FAO, 2004).

As médias das frequências alélicas encontradas nos caprinos locais foram inferiores as reportadas por Li et al. (2002), estudando raças de cabras nativas chinesas $(6,90)$. Para Buchanan et al. (1994) as diferenças que ocorrem nas frequências alélicas entre populações indicam se os marcadores podem ser utilizados para identificar ou alocar indivíduos dentro de raças ou a região de origem. O nível de polimorfismo encontrado nos microssatélites resulta das taxas de mutações que alteram o comprimento destes marcadores, sendo a inserção e deleção as principais fontes dessas mudanças (Schlötterer e Tautz, 1992). Assim, o número de alelos encontrados no marcador influencia diretamente na heterozigosidade esperada e o PIC (Curi, 2001).

Os microssatélites OarFCB304 e SRCRSP8 podem ser utilizados para compor painéis em teste de paternidade, pois apresentaram PIC superior a 0,50 , e resultados satisfatórios referentes à $\mathrm{PE}$, heterozigosidade e equilíbrio.

Os resultados obtidos para o EHW, apresentaram desequilíbrio apenas para o marcador CSSM66. Segundo Martínez et al. (2004) este 
comportamento se deve a grande quantidade de alelos $\mathrm{e}$ as possíveis frequências que são encontradas neste marcador. Também, este desequilíbrio pode ser devido a subdivisão dentro das populações (efeito Wahlund), acasalamentos dirigidos, antepassados comuns, seleção natural, migração ou fluxo de genes a partir de populações externas.

Os marcadores BM1818 e BMM6506 apresentaram-se em diferentes painéis (o primeiro compondo o painel nativo e o segundo exótico), o que permitiu ao final, nove marcadores para cada painel de paternidade, indicando que são bastante informativos, podendo ser utilizado em estudos genéticos dessa natureza de raças caprinas em geral.

No painel proposto apenas o marcador OarFCB304 faz parte do painel já proposto MAPA para teste de paternidade. A IN n. 74 de 2004 do MAPA, exige a utilização de 8 marcadores microssatélites (OarCP49, OarFCB11, OarAE129, OarFCB304, MAF 214, HISTOCOMP. Complex (Hcc) SPS113 e D5S2) para credenciamento de laboratórios para a realização de teste de identificação genética de animais por análise de DNA.

O desenvolvimento de painéis que permitam uma resolução satisfatória vem sendo proposto por outros pesquisadores. Martínez et al. (2005a) a partir de um painel de 22 marcadores microssatélites, desenvolveram um painel de doze microssatélites para cabras Murciano-Granadina, com probabilidade de exclusão combinada (PEC) de 0,999. Silva et al. (2014) propuseram um painel com 16 marcadores microssatélites para teste de paternidade em caprinos locais e comerciais, PE1 e PE2 de 99,98\% e 99,99\%. Vieira et al. (2011) desenvolveu um painel para teste de paternidade em búfalos com 13 marcadores microssatélites para identificação genética e de paternidade em búfalos, o que se demonstrou eficiente.

O painel proposto para caprinos dos grupos locais e exóticos seria composto por 9 microssatélites, com uma PEC superior aos resultados citados anteriormente e com características de PIC, heterosigozidade, EHW satisfatórios para o teste de paternidade. A ISAG recomenda o uso de painéis com no mínimo 12 marcadores microssatélites com PE média de 0,9999. Curi et al. (2002) estudando a viabilidade de aplicação de determinados locos microssatélites para teste de paternidade em bovinos da raça Gir, observou PEC de 0,9789, valor este considerado não adequado para teste de paternidade. Martínez et al. (2005b) a partir dos dados de 24 microssatélites, propuseram um painel básico com 12 microssatélites, cuja probabilidade de exclusão combinada a priori foi de 0,9984 , para ovelhas Palmera e, um painel adicional de 6 microssatélites para controle de filiação para os casos onde não se pode resolver com o painel básico, sendo a PEC para os dois painéis apresentados de 0,99999.

Luikart et al. (1999) desenvolveram dois sistemas de multiplex com onze locos microssatélite para teste de paternidade em caprinos e obtiveram probabilidade de exclusão maior que 0,99999 para rebanhos caprinos da Casemira, 0,99999 para as raças Angorá e Murciano-Granadina, e de 0,99997 para a raça Saanen. Resultado semelhante de probabilidade de exclusão também foi encontrado para a raça Saanen, neste trabalho. Pariset et al. (2003) avaliaram satisfatoriamente $o$ índice de consanguinidade com 11 marcadores microssatélites em 17 rebanhos da raça Sarda Italiana, auxiliando na manutenção dos estoques dessa raça.

Já Silva (2006), analisando duas espécies de porcos-do-mato (Cateto e Queixada), encontrou probabilidade de exclusão combinada de 0,9948. Este valor foi considerado satisfatório para catetos. A probabilidade obtida para o grupo Queixada, apesar de ter sido considerada alta $(0,9553)$, não foi satisfatória, pois os valores mínimos de exclusão de paternidade devem ser iguais ou superiores a 0,999 . Giacomoni (2002), com um sistema de quatro locos microssatélites, obteve probabilidade de exclusão de 0,93 em cavalos pantaneiros, considerada satisfatória, para estudos em paternidade, e para cavalos crioulos, a probabilidade de exclusão combinada foi muito baixa $(0,74)$. Usha et al. (1995) obtiveram probabilidade de exclusão de 0,99 utilizando um painel com cinco microssatélites para teste de paternidade em bovinos. A grande divergência entre as probabilidades de exclusão obtidas para as diferentes espécies se deve ao fato de se utilizar marcadores distintos. Além disso, dentro de raça/espécie cada indivíduo representa uma combinação única de genes.

Os resultados da probabilidade de identidade encontrados para as populações de caprinos locais avaliadas neste estudo apresentaram-se próximas as de Paetkau et al. (1995) estudando a estruturação da população de urso polar encontraram probabilidade de identidade combinada em torno 
de $1,0 \times 10^{-6}-2,1 \times 10^{-7}$. A probabilidade de identidade (PI) do sistema proposto neste trabalho foram inferiores as de Luikart et al. (1999) avaliando quatro raças caprinas (Casemira, Angorá, Saanen e Murciano-Granadina) encontrou PI para o conjunto multiplex em cada população de $2,3 \times 10^{-19}, 5 \times 10^{-19}, 1,4 \times 10^{-15}$ e $2,3 \times 10^{-17}$.

McClure et al. (2012), Silva et al. (2014) relataram que as alterações nos painéis de verificação de parentesco geram custos adicionais, uma vez que reprodutores ativos, genotipados com painéis antigos devem ser re-testados com novos marcadores adicionais, podendo enfrentar limitações, quando se consideram animais antigos sem DNA disponível devido a morte ou mudança de propriedade. Desta forma há necessidade de verificar-se avaliações nos painéis que são propostos nas diferentes populações em constante transformações.

Apesar dos avanços atuais na Genômica, que afetam o desenvolvimento da pecuária $\mathrm{e}$ agricultura, tecnologias simples devem ser associadas as novas para que criadores possam dispor de técnicas que permitam melhorar a qualidade dos rebanhos, diminuindo os custos de produção. Estudos sobre erros de genotipagem são consideradas escassos em caprinos e de extrema importância em programas de melhoramento e conservação, uma vez que a disseminação de material genético errôneo compromete o futuro das raças e da produção animal.

\section{Conflito de Interesse}

Os autores declaram não existir conflito de interesse.

\section{Comitê de Ética}

Os autores declaram que o experimento foi aprovado pela Comissão de Ética no Uso de Animais da Universidad de Cordoba.

\section{Referências}

Belkhir K.; Borsa P.; Chikhi L.; Raufaste N.; Bonhomme F. 2004 GENETIX 4.05, logiciel sous Windows TM pour la génétique des populations. Laboratoire Génome, Populations, Interactions, CNRS UMR 5171, Université de Montpellier II, Montpellier (France). Disponível em: <http://kimura.univmontp2.fr/genetix/>. Acesso em: 07 nov. 2006.

Bishop, M.D.; Kappes, S.M. A genetic linkage map for cattle. Genetics, 136: 619-639, 1994.
Bolstein, D.; White, R.L.; Skolnick, M.; Davis, R.W. Construction of a genetic linkage map in man using restriction fragment length polymorphisms. American Journal of Human Genetics, 32: 314-331, 1980.

Buchanan, F.C.; Adams, L.J.; Littlejohn, R.P.; Maddox. J.F.; Crawford, A.M. Determination of evolutionary relationships among sheep breeds using microsatellites. Genomics, 22: 397-403, 1994.

Carneiro, P.L.S.; Euclides, R. F.; Almeida e Silva, M.; Lopes, P.S.; Torres, R.A.; Torres Filho, R. A.; Carneiro, A. P.S. Efeito de erros de pedigree na seleção. Revista Brasileira de Zootecnia, 28(2): 269-274, 1999.

Chamberlain, J.S.; Gibbs, R. A.; Ranier, J.E.; Nguyen, P.N.; Caskey, C.T. Deletion screening of the Duchenne muscular dystrophy locus via multiplex DNA amplification. Nucleic Acid Research, 16: 11141-11156, 1988.

Curi, R.A.; Lopes, C.R. Teste de paternidade em bovinos. Revista Biotecnologia Ciência \& Desenvolvimento, 21: 41-45, 2001.

Curi, R.A.; Lopes, C.R. Evaluation of nine microsatellite loci and misidentification paternity frequency in a population of $\mathrm{Gyr}$ breed bovines. Brazilian Journal of Veterinary Research and Animal Science, 39(3): 129-135, 2002.

DeNise, S.; Johnston, E.; Halverson, J.; Marshall, K.; Rosenfeld, D.; McKenna, S.; Sharp, T.; Edwards, J. Power of exclusion for parentage verification and probability of match for identity in American kennel club breeds using 17 canine microsatellite markers. International Society for Animal Genetics. Animal Genetics, 35: 14-17, 2004.

Dzialuk, A.; Chybicki, I.; Burczyk, J. PCR Multiplexing of nuclear microsatellite loci in Quercus species. Plant Molecular Biology Reporter, 23: 121-128, 2005

Edwards, M.C.; Gibbs, R.A. Multiplex PCR: advantages, development, and applications.

Genome Research, 3: S65-S75, 1994.

FAO. Secondary Guidelines for Development of National Farm Animal Genetic Resources Management Plans: Measurement of Domestic Animal Diversity (MoDAD): Recommended Microsatellite Markers, FAO. Rome. 2004. Disponível em: <http://www.fao.org/3/a-aq569e.pdf $>$. Acesso em: 10 nov. 2010 . 
FAO. Food and Agriculture Organization of the United Nations. (2008). DOMESTIC ANIMAL DIVERSITY INFORMATION SYSTEM. Disponível em: <http://dad.fao.org>.http://www.fao.org/ag/a gainfo/programmes/es/A5.html . Acesso em: 10 nov. 2010.

FAO. Guidelines for development of National Management of Farm Animal Genetic Resources Plans: Measurement of Domestic Animal Genetic Diversity (MoDAD): recommended microsatellite markers. Rome, Italy, 2004.

Giacomoni, E.H.; Fernández-Stolz, G.P.; Freitas, T.R.O. Genetic diversity in the Pantaneiro horse breed assessed using microsatellite DNA markers. Genetics and Molecular Research, 7: 261-270, 2002.

Guo, S.W.; Thompson, E.A. Performing the exact test of Hardy-Weinberg proportions for multiple alleles. Biometrics, 48: 361-372, 1992.

ISAG - International Society for Animal Genetics. (2002). Disponível em: <http://www.isag.org.uk 2002>. Acesso em: 12 dez. 2007.

ISAG - International Society for Animal Genetics. (2016). Disponível em: <http://www.isag.org.uk 2016>. Acesso em: 15 jan. 2017.

Jamieson, A. The effectiveness of using codominant polymorphic allelic series for (1) checking pedigrees and (2) distinguishing full-sib pair members. Animal Genetics, 25: 37-44, 1994.

Li, M.; Zhao, S.; Bian, C.; Wang, H.; Wei, H.; Liu, B.; Yu, M.; Fana, B.; Chen, L.; Zhu, M.; Li, S.; Xiong, T.; Li, K. Genetic relationships among twelve Chinese indigenous goat populations based on microsatellite analysis. Genetics Selection Evolution, 34: 729-744, 2002.

Lins, T.C.L.; Soares, C.N.; Guimarães, C.S.; Ribeiro, M.A.N.; Diener, P.S.A.; Ferreira, M.E.; Gattaplaglia, D. Diversidade alélica e desempenho forense de um conjunto de multiplex de 11 marcadores microssatélites em populações bovinas de Nelore e Gir (Bos indicus). Genomax: Tecnologia Genômica, 2006.

Luikart, G.; Biju-Duval, M.P.; Ertugru, O. Power of 22 microssatelite marker in fluorescent multiplex for parentage testing in goats
(Capra hircus). Animal Genetics, 30: 431438, 1999.

MAPA. Ministério da Agricultura, Pecuária e Abastecimento. Instrução Normativa. n. 74. $2004 . \quad$ Disponível em: $<\mathrm{http}$ ///extranet.agricultura.gov.br/sislegisconsulta/consultarLegislacao.do>. Acesso em: 15 jan. 2007.

Marshall, T.C.; Slate, J.; Kruuk, L.; Pemberton, J.M. Statistical confidence for likelihood based paternity inference in natural populations. Molecular Ecology, 7: 639-655, 1998.

Marshall, T.C.; Sunnucks, P.; Spalton, J. A.; Greth, A.; Pemberton, J.M. Use of genetic data for conservation management: the case of the Arabian oryx. Animal Conservation, 2: 269278, 1999.

Martínez, A.M.; Carrera, M. P.; Acosta, J.M.; Rodriguez-Gallardo, P.P.; Cabello, A.; Camacho, M.E.; Delgado, J.V. Genetic characterisation of the Blanca Andaluza Goats base on microsatellite markers. South African Journal of Animal Science, 34(1): 17-19, 2004.

Martínez, A.M.; Vega-Pla, J.L.; Bravo, M.J.; Barba, C.; Caraballo, J.; Delgado, J.V. Caracterización genética de la oveja Palmera con microsatélites. Archivos de Zootecnia, 54: 363-367, 2005b.

Martínez, A.M.; Vega-Pla, J.L.; Lozano, J.M.; Carrera, M.P.; Acosta, J.M.; A. Cabello. Caracterización genética de la cabra Murciano-Granadina con microssatélites. Archivos de Zootecnia, 54: 327-331, 2005a.

McClure, M.; Sonstegard, T.; Wiggans, G.; Van Tassell, C.P.; Imputation of microsatellite alleles from dense SNP genotypes for parental verification. Frontiers in Genetics, 3: 140, 2012.

Menezes, M.P.C.; Martínez, A.M.; Ribeiro, M.N.; Pimenta Filho, E.C.; Bermejo, J.V.D. Caracterização genética de raças caprinas nativas brasileiras utilizando 27 marcadores microssatélites. Revista Brasileira de Zootecnia, 35(4): 1336-1341, 2006.

Mommens, G.W.; Coppieters, A. Dinucleotide repeat polymorphism at the bovine MM12E6 and MM8D3 loci. Animal Genetics, 25: 368, 1994.

Moore, S.S.; Byrne, K. Characterization of 65 bovine microsatellites. Mammalian Genome, 5: 84-90, 1993. 
Oliveira, J.C.V.; Ribeiro, M.N.; Rocha, L.L.; GomesFilho, M.A.; Delgado, J.V.; Martinez, A.M.; Menezes, M.P.C.; Bettencourt, C.M.; Gama, L.T.; Rocha, L. L. Genetic relationships between two homologous goat breeds from Portugal and Brazil assessed by microsatellite markers. Small Ruminant Research, 93: 79-87, 2010.

Paetkau, D.; Calvert, W.; Stirling't, I.; Strobeck, C. Microsatellite analysis of population structure in Canadian polar bears. Molecular Ecology, 4: 347-354, 1995.

Pariset, L.; Savarese, M. C.; Cappuccio, I.; Valentini, A. Use of microsatellites for genetic variation and inbreeding analysis in Sarda sheep flocks of central Italy. Journal of Animal Breeding and Genetics, 120: 425232, 2003.

Park, S. D. E. Trypanotolerance in West African cattle and the population genetic effect of selection [Ph.D. thesis]. University of Dublin. 2001.

Raymond, M.; Rousset, F. Genepop: populations genetics software for exact tests and ecumenicism. Journal Heredity, 86: 248249, 1995.

Schlötterer, C.; Tautz, D. Slippage symthesis of simple sequence DNA. Nucleic Acids Research, 20: 211-215, 1992.

Silva, E.C. da; McManus, C.M; Paiva Guimarães, M.P.S.L.M de P.; Gouveia, A.M.G.; Facó, O.; Pimentel, D.M.; Caetano, A.R.; Paiva, S.R. Validation of a microsatellite panel for parentage testing of locally adapted and commercial goats in Brazil. Genetics and Molecular Biology, 37(1): 54-60, 2014.

Thieven, U.; Solinas-Toldo, S. Polymorphic CAmicrosatellites for the integration of the bovine genetic and physical map. Mammalian Genome, 8: 52-55, 1997.
Tommasini, L.; Batley, J; Arnold G.M; Cooke, RJ; Donini P; Lee D.; Law, JR; Lowe C; Moule C.; Trick, M.; Edwards K.J. The development of multiplex simple sequence repeat (SSR) markers to complement distinctness, uniformity and stability testing of rape (Brassica napus L.) varieties. Theoretical and Applied Genetics, 106: 1091-1101, 2003.

Usha, A.P.; Simpson, S.P.; Williams, J.L. Probability of random sire exclusion using microssatelite markers parentage verification. Animal Genetics, 26: 155-161, 1995.

Vaiman, D.; Mercier, D.; Moazami-Goudarzi, K.; Eggen, A.; Ciampolini, R.; Lépingle, A.; Velmala, R.; Kaukinen, J.; Varvio, S.L.; Martin, P.; Levéziel, H.; Guérin, G. A set of 99 cattle microsatellites: characterization, synteny mapping, and polymorphism. Mammalian Genome, 5: 288-97, 1994.

Vieira, J.N.; Texeira, C.S.; Kuabara, M.Y.; Oliveira, D.A.A. Importância de teste de DNA para verificação de parentesco em Búfalos (Bubalus bubalis). Pubvet, 5(2): 999-1004, 2011.

Wagner, H. W.: Sefc, K. M. Identity. 1999. Disponível em: <http://www.boku.ac.at/zag/identity> Acesso em: 10 nov. 2008.

Waits, L.P.; Luikart, G.; Taberlet, P. Estimating the probability of identity among genotypes in natural populations: cautions and guidelines. Molecular Ecology, 10: 249-256, 2001.

Yang, L.; Zhao, S.H.; Li, K.; Peng, Z.Z; Montgomery, G.W. Determination of relationships among five indigenous Chinese goat breeds with six microsatellite markers. Animal Genetics, 30(6): 452-456, 1999. 